\section{Shape of Pulses of Radio-frequency Radiation from the Sun}

DURING some 400 hours observations of solar radiation on $75 \mathrm{Mc} / \mathrm{s}$., the variation of the second detector anode current was recorded with a portable vibration galvanometer tuned to resonance at about $45 \mathrm{c} . \mathrm{s}$. and damped less than critically, but so that the spot became stationary after sudden deflexions in less than $0.25 \mathrm{sec}$. Records were taken on $35 . \mathrm{mm}$. film moving $12 \cdot 1 \mathrm{~mm} . / \mathrm{min}$. The gain was adjusted so that the current due to noise generated in the receiver was about 15 per cent of the maximum allowable, to avoid distortion in all but exceptional cases.

Ninety-nine single pulses of radiation lasting a few seconds each were observed sufficiently clear of overlapping pulses to give reason to believe that their shape on the film was a faithful record (by the linear detector) of the variation of radiated power from the source of the solar noise.

The 'tail' of such a pulse may indicate the manner of decrease in radiation by the source when it is no longer subject to the influence of an exciting agency, or, if the decay of the source under such conditions is very rapid, the curve will simply reflect the decrease in influence of the exciting agency. An analysis of the shape of the 'tails' of 78 such pulses was made after projecting the record, with magnification about $30 \times$, and tracing the centre line of the photographic trace of the galvanometer spot. Twenty-one were not analysed, for the reason that the height of the pulse peak above background was less than 25 per cent of the background value, and too short a length of falling slope was available to enable significant measurements to be made. Fifty-eight were found to be very probably exponential in shape, eleven less probably so, four probably not so and five definitely not.

Between three-quarters and nine-tenths of the portion of the broken-line curve in the accompanying figure was analysed, and the deviation from average of the factor $x$ in exp $(-x t)$ was less than \pm 15 per cent for those assumed to have exponential form.

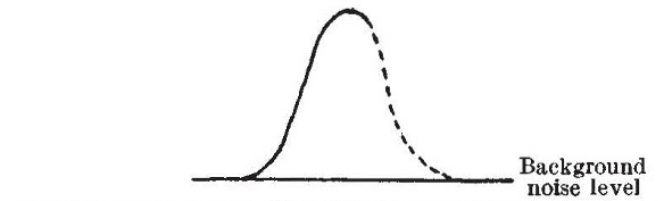

TyPiCAL PULSE SHAPE. PORTION OF CURVE EXaMined, - - -

The times taken for radiated power to decrease to half in the pulses of exponential shape are tabulated below :

\begin{tabular}{|c|c|c|c|c|c|c|c|c|c|c|}
\hline $\begin{array}{c}\text { Half-life } \\
\text { (sec.) }\end{array}$ & $\begin{array}{l}0.4- \\
0.6\end{array}$ & $\begin{array}{l}0.6- \\
0.8\end{array}$ & $\begin{array}{l}0.8- \\
1.0\end{array}$ & $\begin{array}{l}1.0- \\
1.2\end{array}$ & $\begin{array}{l}1 \cdot 2- \\
1 \cdot 4\end{array}$ & $\begin{array}{l}1 \cdot 4- \\
1 \cdot 6\end{array}$ & $\begin{array}{l}1 \cdot 6- \\
1 \cdot 8\end{array}$ & $\begin{array}{l}1 \cdot 8- \\
2 \cdot 0\end{array}$ & $\begin{array}{l}2 \cdot 0- \\
2 \cdot 2\end{array}$ & $\begin{array}{c}\text { Over } \\
2 \cdot 2\end{array}$ \\
\hline $\begin{array}{l}\text { No. of } \\
\text { pulses }\end{array}$ & 5 & 8 & 12 & 13 & 8 & 7 & 3 & 0 & 2 & nil \\
\hline
\end{tabular}

Included in the table above are thirty pulses occurring either consecutively, or within a short interval. These follow :

\begin{tabular}{rl}
\multicolumn{1}{c}{ Date } & Time interval \\
27.5 .47 & 30 sec. (con.) \\
4.6 .47 & $30 \mathrm{sec}$ (con.) \\
22.7 .47 & $30 \mathrm{sec}$. (con.) \\
23.7 .47 & $1 \mathrm{~min}$. (con.) \\
25.7 .47 & $30 \mathrm{sec}$ (con.) \\
7.8 .47 & $30 \mathrm{sec}$ (con.) \\
7.8 .47 & $30 \mathrm{sec}$ (con.) \\
12.8 .47 & $40 \mathrm{sec}$. \\
30.9 .47 & $5 \mathrm{~min}$. \\
30.9 .47 & $1 \mathrm{~min}$. \\
30.9 .47 & $30 \mathrm{sec}$. (con.) \\
$\mathbf{3 0 . 9 . 4 7}$ & $30 \mathrm{sec}$.
\end{tabular}

Although it might be assumed that pulses closely connected in time come from the same region and should therefore show similar half-value times, the results given above do not offer firm support for such a hypothesis.

No success was obtained from attempts to interpret the rising portion of the pulse curve in terms of exponential functions.

Physics Department,

S. E. Williams

University of Western Australia,

Nedlands, Western Australia.

Dec. 12.

\section{Spectrum of lodine Oxide (IO) in Flames}

BANDS attributed to iodine oxide (IO) were observed by Vaidya ${ }^{1}$ in a flame of methyl iodide, and analysed into two systems, $A$ and $B$. More recently, Blake and Iredale ${ }^{2}$ have published a revised analysis for system $A$; when this formula was used to arrange the bands, an obviously unsatisfactory intensity distribution was obtained. We have re-measured the bands, and extended the system to longer wavelengths. It is now found that all the bands can be arranged into one system instead of two, this system being an extension of the $B$ system, with modified values of $v^{\prime \prime}$. The bands are listed in the accompanying table; intensities are visual estimates making some allowance for variations of plate sensitivity with wave-length.

BAND HEADS OF IO

\begin{tabular}{|c|c|c|c|c|c|c|c|}
\hline$\lambda$ & Int. & $v$ & $v^{\prime}, v^{\prime \prime}$ & $\lambda$ & Int. & v & $v^{\prime}, v^{\prime \prime}$ \\
\hline $4189 \cdot 0$ & 5 v.d. & 23865 & 5,0 & $5208 \cdot 8$ & 5 & 19193 & 2,5 \\
\hline $4286 \cdot 2$ & $7 \mathrm{~d}$ & $23422 \cdot 5$ & 4,0 & $5248 \cdot 7$ & 1 & 19047 & 3,6 \\
\hline $4355 \cdot 9$ & 9 & 22951 & 3,0 & $5307 \cdot 5$ & 10 & 18836 & 0,4 \\
\hline $4396 \cdot 7$ & $6 \mathrm{~d}$ & 22738 & 4,1 & 5345 & 1 & 18704 & 1,5 \\
\hline $4448 \cdot 7$ & 7 & 22472 & 2,0 & $5385 \cdot 5$ & 2 & 18563 & 2,6 \\
\hline $4487 \cdot 7$ & 10 & 22277 & 3,1 & 5422 & 4 & 18438 & 3,7 \\
\hline $4548 \cdot 1$ & 3 & 21981 & 1,0 & 5495 & 9 & 18192 & 0,5 \\
\hline $4586 \cdot 7$ & 10 & 21796 & 2,1 & 5533 & 7 & 18069 & 1,6 \\
\hline $4624 \cdot 9$ & 5 & 21616 & 3,2 & $5655 \cdot 5$ & 2 & 17677 & 4,9 \\
\hline $4668 \cdot 3$ & 2 & 21415 & 4,3 & 5692 & 7 & 17565 & 0,6 \\
\hline $4693 \cdot 5$ & 9 & 21300 & 1,1 & 5730 & 8 & 17447 & 1,7 \\
\hline $4731 \cdot 2$ & 7 & $21130 \cdot 5$ & 2,2 & 5767 & 4 & 17334 & 2,8 \\
\hline $4763 \cdot 3$ & $4 d$ & 20988 & 3,3 ? & 5900 & 5 & 16945 & 0,7 \\
\hline $4806 \cdot 1$ & 3 & 20801 & 0,1 & 5939 & 6 & 16832 & 1,8 \\
\hline $4844 \cdot 5$ & 10 & 20636 & 1,2 & 5976 & 7 & 16729 & 2,9 \\
\hline $4920 \cdot 9$ & 3 & 20316 & 3,4 & $6152 \cdot 5$ & 3 & 16240 & 1,9 \\
\hline $4963 \cdot 6$ & 6 & 20141 & 0,2 & 6193 & 4 & 16142 & 2,10 \\
\hline $5002 \cdot 3$ & 6 & 19985 & 1,3 & $6231 \cdot 5$ & 4 & 16043 & 3,11 \\
\hline $5049 \cdot 8$ & 2 & 19797 & 2,4 & 6273 & $3 d$ & 15937 & 4,12 \\
\hline $5131 \cdot 0$ & 9 & 19484 & 0,3 & & & & \\
\hline
\end{tabular}

The following are the molecular constants:

$$
\begin{aligned}
& v_{e}=21,565 \mathrm{~cm}^{-1} \omega_{e}^{\prime \prime}=687 \mathrm{~cm}^{-1} x_{e}^{\prime \prime} \omega_{e}^{\prime \prime}=5 \mathrm{~cm} .^{-1} \\
& \omega_{e}^{\prime}=512 \mathrm{~cm} .^{-1} x_{e} \omega^{\prime}=5 \mathrm{~cm}^{-1}
\end{aligned}
$$

A graphical Birge - Sponer extrapolation gives a dissociation energy for the ground-state, $D_{0}=1.9 \pm$ $0 \cdot 2 \mathrm{eV}$. or $44 \mathrm{k} . c a l$. Bands with $v^{\prime}=4$ are diffuse, and the 5,0 band is very diffuse; this is probably due to pre-dissociation. The band system for IO is now closely analogous to the systems recently reported $^{3,4}$ for $\mathrm{ClO}$ and $\mathrm{BrO}$. This analysis gives a normal vibrational intensity distribution as shown in Fig. 2. The IO bands have been obtained when iodine is added to an oxyhydrogen flame, thus supporting the assignment to IO and eliminating CI.

When iodine is added to a methyl alcohol/air flame a strong band, or region of continuum, with a sharp 